\title{
Copolymerization of Carbon-carbon Double-bond Monomer (Styrene) with Cyclic Monomer (Tetrahydrofuran)
}

\author{
F. Sari *, M. I. Ferrahi, M. Belbachir \\ Laboratoire de Chimie des Polymères, Département de Chimie, Faculté des Sciences, Université d'Oran \\ Es-Sénia BP N 1524 El M’Naouar, 31000 Oran, Algerie
}

Received: 29th October 2012; Revised: 29th November 2012; Accepted: 29th November 2012

\begin{abstract}
We reported in this work that the cationic copolymerization in one step takes place between carbon-carbon double-bond monomer styrene with cyclic monomer tetrahydrofuran. The comonomers studied belong to different families: vinylic and cyclic ether. The reaction is initiated with maghnite- $\mathrm{H}^{+}$an acid exchanged montmorillonite as acid solid ecocatalyst. Maghnite- $\mathrm{H}^{+}$is already used as catalyst for polymerization of many vinylic and heterocyclic monomers. The oxonium ion of tetrahydrofuran and carbonium ion of styrene propagated the reaction of copolymerization. The acetic anhydride is essential for the maintenance of the ring opening of tetrahydrofuran and the entry in copolymerization. The temperature was kept constant at $40{ }^{\circ} \mathrm{C}$ in oil bath heating for 6 hours. A typical reaction product was analyzed by ${ }^{1} \mathrm{H}-\mathrm{NMR},{ }^{13} \mathrm{C}-\mathrm{NMR}$ and IR and the formation of the copolymer was confirmed. The reaction was proved by matched with analysis. The maghnite- $\mathrm{H}^{+}$allowed us to obtain extremely pure copolymer in good yield by following a simples operational conditions. (C) 2012 BCREC UNDIP. All rights reserved.
\end{abstract}

Keywords: Hybrid copolymerization, Molecular engineering, Poly(St-co-THF), Styrene copolymer, maghnite

How to Cite: F. Sari, M.I. Ferrahi, M. Belbachir (2012). Copolymerization of Carbon-carbon Double-bond Monomer (Styrene) with Cyclic Monomer (Tetrahydrofuran) . Bulletin of Chemical Reaction Engineering \& Catalysis, 7(2): 165-171. (doi:10.9767/bcrec.7.2.4074.165-171)

Permalink/DOI: http://dx.doi.org/10.9767/bcrec.7.2.4074.165-171

\section{Introduction}

The copolymerization is very important from the technological viewpoint. It allows the polymers scientists to prepare custom polymers products with specifically desired properties. They can vary, in very broad proportions, the physical properties and the technological characteristics of polymeric materials by copolymerization of monomers having different chemical structures. The copolymerization between cyclic monomers and carbon-carbon double-bond monomers is not well studied [1].

Tsukamoto et al. [2] reported that random copolymerization takes place between monomers polymerizing through oxonium ion with carbonium ion. Some rare examples are quoted in this work like the copolymerization of styrene (St) with some cyclic monomers. The St polymerizing through carbonium ion, can be copolymerized with many others monomers polymerizing through oxonium ion: B-propiolactone; 1,3-dioxolane;

\footnotetext{
* Corresponding Author. E-mail: sa.fouad@live.fr (F. Sari)
} 
Trioxane; tetraoxane; isobutylene oxide ; propylene oxide; styrene oxide; epichlorohydrin. Such copolymerizations would require a careful selection of the monomers and reaction conditions to closely match the reactivities of the different monomers and propagating centers [1].

To realize this kind of reaction, the copolymerization of St with tetrahydrofuran (THF) has been investigated. The poly(St) (PSt) and poly(THF) (PTHF) are highly coveted for their distinctly remarkable properties and are produced on a great industrial scale [1-3]. Different copolymers containing chains of St and THF are synthesized:

- Example 1: Hazer [4] obtain branched homo and block polymers with the multifunctional initiator, bis(3,5-dibro-momethyl benzoyl) peroxide, is therefore synthesized and used in the cationic polymerization of THF to prepare branched poly(THF) having the peroxide group in the chain with four arms. He Synthesis two, a StTHF lin-ear block copolymers by using difunctional cationic initiators, bis(4bromomethyl benzoyl) peroxide and 2,5dimethyl 2,5-di(4-bromomethyl benzoyl) peroxyhexane [5]. The PTHF initiates the thermal polymerization of $\mathrm{St}$ to give branched block copolymers.

- Example 2: The graft copolymer of St with PTHF as branch chain is prepared by atom transfer radical polymerization (ATRP) of St and PTHF with an end-standing methacrylate (MA-THF) synthesized cationically [6].

- Example 3: Cianga et al. [7] use a bifunctional initiator (1,4-dibromo-2,5-bis(bromomethyl) benzene) for cationic ring opening polymerization (CROP) of THF and for ATRP of St, each one separately, for result to a macromonomers containing labile groups in the center. After that, the cross-coupling reaction is realized between these two macromonomers to obtain the Poly(p-phenylene) with alternating PSt and PTHF side chains.

- Example 4: Cross-linked PSt with PTHF chains is prepared from St with PTHF macromonomers containing St in end chain. The cross-linkers used are: 1,4-bis[4vinylphenoxy]butane or divinylbenzene by suspension polymerization. The St-PTHF macromonomers can be prepared by cationic polymerization of THF in presence of 4vinylbenzyl bromide or 4-(4-vinylphenoxy)butyl iodide activated by silver hexafluoroantimonate and or 4-(5-hydroxypentyl)styrene activated by triflic anhydride. Alternatively, PS grafted PTHF can also be directly prepared from 5- hydroxypentyl JandaJel by cationic polymerization using triflic anhydride as the initiator [8].

In this work, the copolymer of St with THF was synthesized with a new way. St polymerizes by the radical, cationic or anionic way [1] while the THF polymerizes only by the CROP [9]. For that, an acid catalyst must be used in order to promote a cationic medium and have the desired copolymer. The work published by Ouis et al. [9] display indications that can be incorporated into our experiments: To have a PTHF with rates of conversion around 10\%, 4\% molar of acetic anhydride (AA) compared to the THF was added. The reaction was initiated with $10 \%$ in mass of maghnite- $\mathrm{H}^{+}\left(\mathrm{Mag}-\mathrm{H}^{+}\right)$compared to the monomer. The mixture was stirred at room temperature for 6 hours. The amount of catalyst can be decrease in order to have products with great molar masses.

The solid catalysts are often used to guide the selectivity of the reactions in ways very specific [10]. Mag- $\mathrm{H}^{+}$[11] is a high activated acid bentonite montmorillonite catalyst. It may be used successfully as solid source of protons catalysts to polymerize a vinyl and cyclic ether monomers. This solid catalyst has many advantages. Among them, is to give a small polydispersity index of polymers and there are no traces of initiator in the product obtained.

In this work, the Mag- $\mathrm{H}^{+}$is used for the initiation of cationic copolymerization of the carbon -carbon double-bond St with cyclic monomers THF in one step. The reaction can be proved by concordance with the analyses of the end product.

\section{Materials and Methods}

\subsection{Materials}

St (99\%), THF (99\%), and AA (99\%) were used as purchased from Aldrich.

\subsection{Preparation of $\mathrm{Mag}-\mathrm{H}^{+}$}

The preparation of the Mag- $\mathrm{H}^{+}$was carried out by using a method similar to that described by Belbachir et al. [11]. Indeed, the raw-maghnite (20 g) was crushed for 20 min using a Prolabo ceramic balls grinder. It was then dried by baking at $105^{\circ} \mathrm{C}$ for $2 \mathrm{~h}$. The maghnite was then weighed and placed in an Erlenmeyer flask together with 500 $\mathrm{ml}$ of distilled water. The maghnite/water mixture was stirred using a magnetic stirrer and combined with sulfuric acid, until saturation was achieved over 2 days at room temperature, the mineral was washed with water until it became sulfate free and then dried at $150{ }^{\circ} \mathrm{C}$. The concentration $0.23 \mathrm{M}$ of 
sulfuric acid treatment solution was used to prepare Mag- $\mathrm{H}^{+}{ }^{\circ} 0.23 \mathrm{M}$ '.

Maghnite treated is hygroscopic; the presence of water trace makes him lose its effectiveness. For that, before each use, maghnite activated must be put in the drying oven with $105{ }^{\circ} \mathrm{C}$ during two days, to eliminate the maximum of water.

\subsection{Synthesis Copolymer of St with THF}

Two experiments were carried out in atmospheric pressure and without solvent. The THF and the St were introduced into a small flask with equimolar amounts. $5 \%$ in masse of $\mathrm{Mag}-\mathrm{H}^{+}$ was added and the mixture was stirred. The temperature was kept constant at $40{ }^{\circ} \mathrm{C}$ in oil bath heating for 6 hours. The same conditions in the first experience were taken again for the second, just; the amount of monomers was changed: $70 \%$ of St with $30 \%$ of $\mathrm{THF}$ and $5 \%$ in mole of AA (/THF) was added. The products obtained were dissolved in THF. Mag- $\mathrm{H}^{+}$can be easily separated from the polymer by filtration. The solution was then dried by evaporation. The used catalyst can be regenerated by heating to a temperature above $100{ }^{\circ} \mathrm{C}$. The yield can be deduced by the mass ratio between copolymer and monomers. The experimental conditions used are summarized in the following table (Table 1).

\subsection{Characterization}

An investigation was devoted to the analysis of the products from the experiments. The characterization was made using many analyses. Measurements of ${ }^{1} \mathrm{H}$ and ${ }^{13} \mathrm{C}$ NMR spectra were conducted in $\mathrm{CDCl}_{3}$ solution under ambient temperature on an AC 300 MHZ Bruker

Table 1: Experimental conditions of the experiments

\begin{tabular}{|c|c|c|}
\hline \multirow{2}{*}{ Conditions } & \multicolumn{2}{|c|}{ Experiments } \\
\hline & $\mathbf{E}_{1}$ & $\mathbf{E}_{2}$ \\
\hline THF (Molar \%) & 50 & 30 \\
\hline St (Molar \%) & 50 & 70 \\
\hline Mag-H+ (Mass \%) & 5 & 5 \\
\hline AA $(\text { Molar \%) })^{2}$ & 0 & 5 \\
\hline Temperature $\left({ }^{\circ} \mathrm{C}\right)$ & 40 & 40 \\
\hline Time (h) & 6 & 6 \\
\hline
\end{tabular}

${ }^{1}$ percentage in mass of Mag- $H^{+}$compared to the overall assets of the monomers.

${ }^{2}$ percentage in mole of the AA compared to the amount of mole of THF put in the reaction. spectrometer using tetramethylsilane (TMS) as internal standard. IR absorption spectrum was recorded on JASCO FT-IR-4200 spectrometer using the $\mathrm{KBr}$ pressed disc technique between the ranges of 400 to $4000 \mathrm{~cm}^{-1}$.

\section{Results and Discussion}

\subsection{Interpretation of Analysis}

The yields obtained are around 14 and $43 \%$ of the samples of the products $\mathrm{E}_{1}$ and $\mathrm{E}_{2}$ respectively. The spectrometric analyses ${ }^{1} \mathrm{H}-\mathrm{RMN}$ obtained from samples $\mathrm{E}_{1}$ and $\mathrm{E}_{2}$ are presented in the followings figures 1 and 2. In the first spectrum (Figure 1), there was poly(St) in conformity with the results published by Verebelyi et al. [12].

Signals assigned to repeating unit of St chain moiety (methine at $\delta=1.45 \mathrm{ppm}$, methylene at $\delta=$ $1.87 \mathrm{ppm}$ and phenyl at $\delta=6.60-7.06 \mathrm{ppm}$ ). The peak at $\delta=7.27 \mathrm{ppm}$ was of deuterated solvent $\mathrm{CDCl}_{3}$. A second peak at $\delta=1.55 \mathrm{ppm}$ was allotted to the water traces in the $\mathrm{CDCl}_{3}$ used according to the work published by Gottlieb et al. [13]. In the second spectrum (Figure 2), there was copolymer of St with THF. This interpretation is in conformity with the results published by Hazer [4] and YanMing et al. [6].

All the lasts signals in the first spectra appear in the second with a small difference. Also, the signals assigned to repeating unit of THF moiety in a copolymer were seen (methylenes in position 3;4 at $\delta=1.64 \mathrm{ppm}$ and the two other $\mathrm{CH}_{2}$ in position $2 ; 5$ at $\delta=3.44 \mathrm{ppm})$. The presence of AA in the end chain from fraction of PTHF was illustrated by signals (methyl $\mathrm{CO}-\mathrm{CH}_{3}$ at $\delta=2.07 \mathrm{ppm}$ and methylene related to acetate $\mathrm{CH}_{2}-\mathrm{O}-\mathrm{CO}$ at $\delta=4.11$ ppm who prove the opening of THF ring with the small peaks). The peaks at $\delta=1.23$ and $1.26 \mathrm{ppm}$ were assigned to methylenes in position $4 ; 5$ of THF linked to St.

It's not already obvious to prove by NMR that there are no traces of monomers for analyzing polymer simple. The interpretation of NMR spectra of polymer solutions generally follows the same approach as for smaller molecules [14]. But here, no traces of monomers can be proven in the samples analyzed. The absence of peaks between $\delta$ $=5.0$ and $6.2 \mathrm{ppm}$ in the two spectra, proves the disappearance of the double connection $(\mathrm{C}=\mathrm{C})$ of ethylene and that shows that St was polymerized. And there weren't other reagents which remained in the analyzed samples, because the St was the last reagents drawn aside from the product during drying by its dominant boiling point.

The presence of the AA for the ring opening polymerization of THF by Mag- $\mathrm{H}^{+}$is essential [9]. This phenomenon was repeated in this 


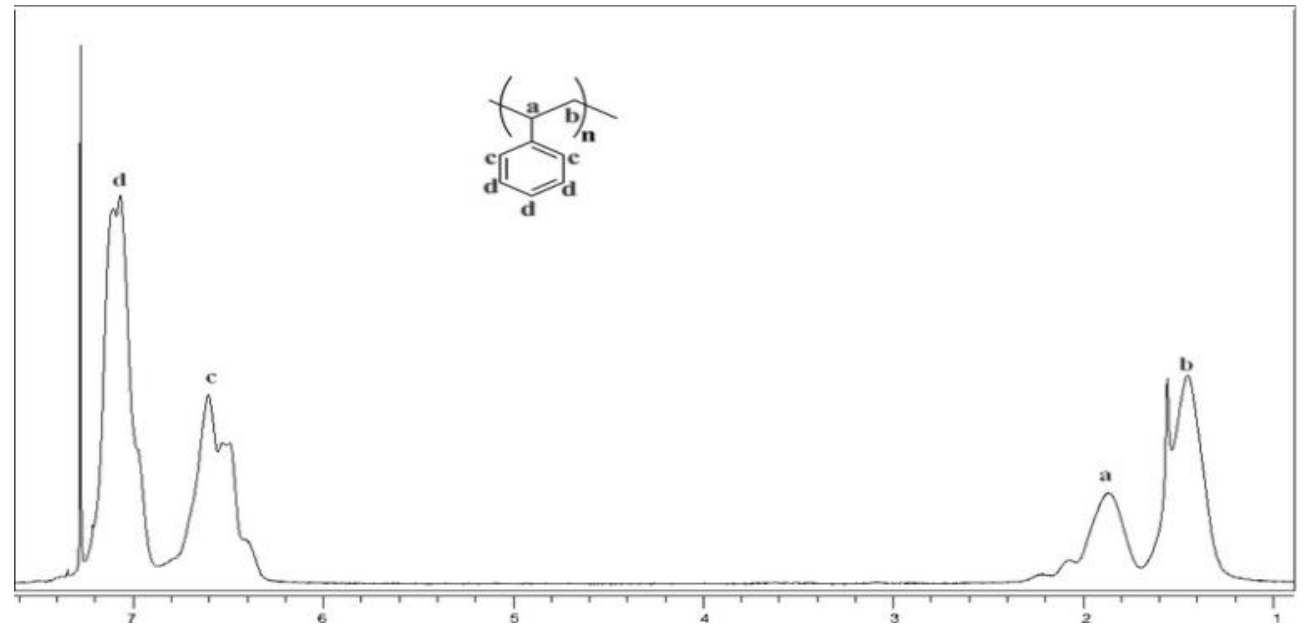

Chemical shift [ppm]

Figure 1: ${ }^{1} \mathrm{H}-\mathrm{NMR}(300 \mathrm{MHZ})$ in $\mathrm{CDCl}_{3}$ of Poly(St) (Sample $\mathrm{E}_{1}$ )

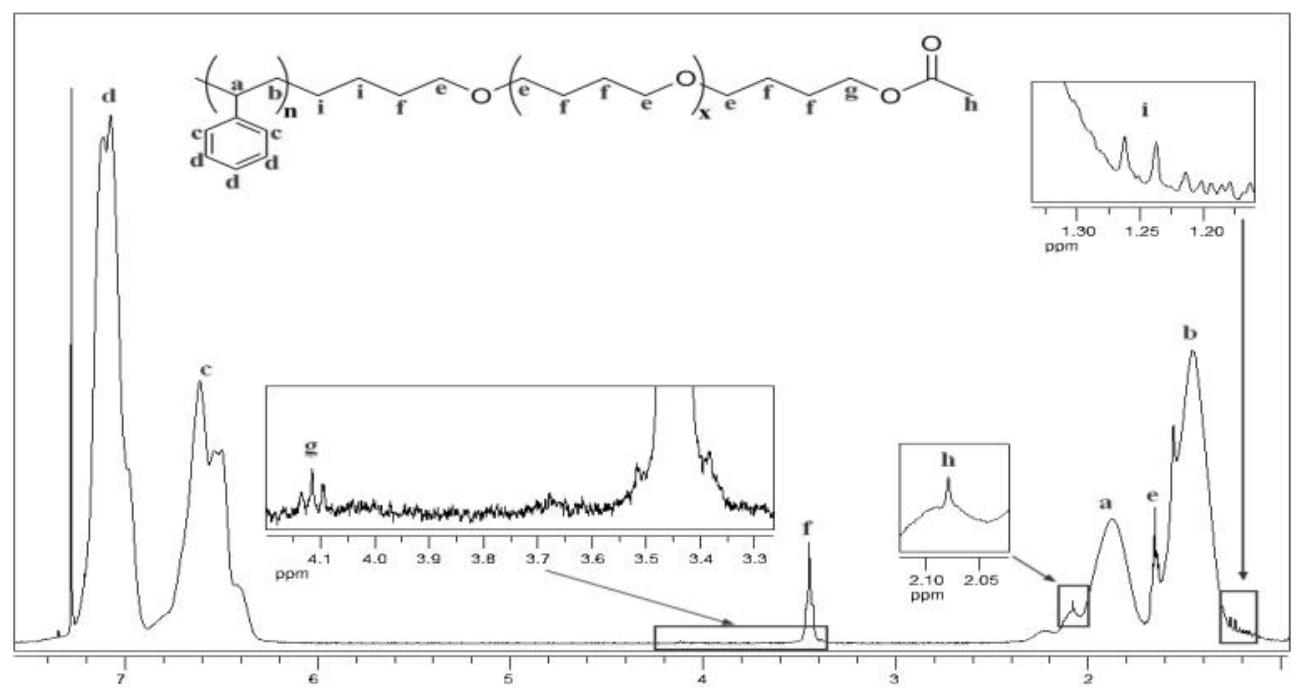

Chemical shift [ppm]

Figure 2: ${ }^{1} \mathrm{H}-\mathrm{NMR}(300 \mathrm{MHZ})$ in $\mathrm{CDCl}_{3}$ of Poly(St-co-THF) (Sample $\mathrm{E}_{2}$ )

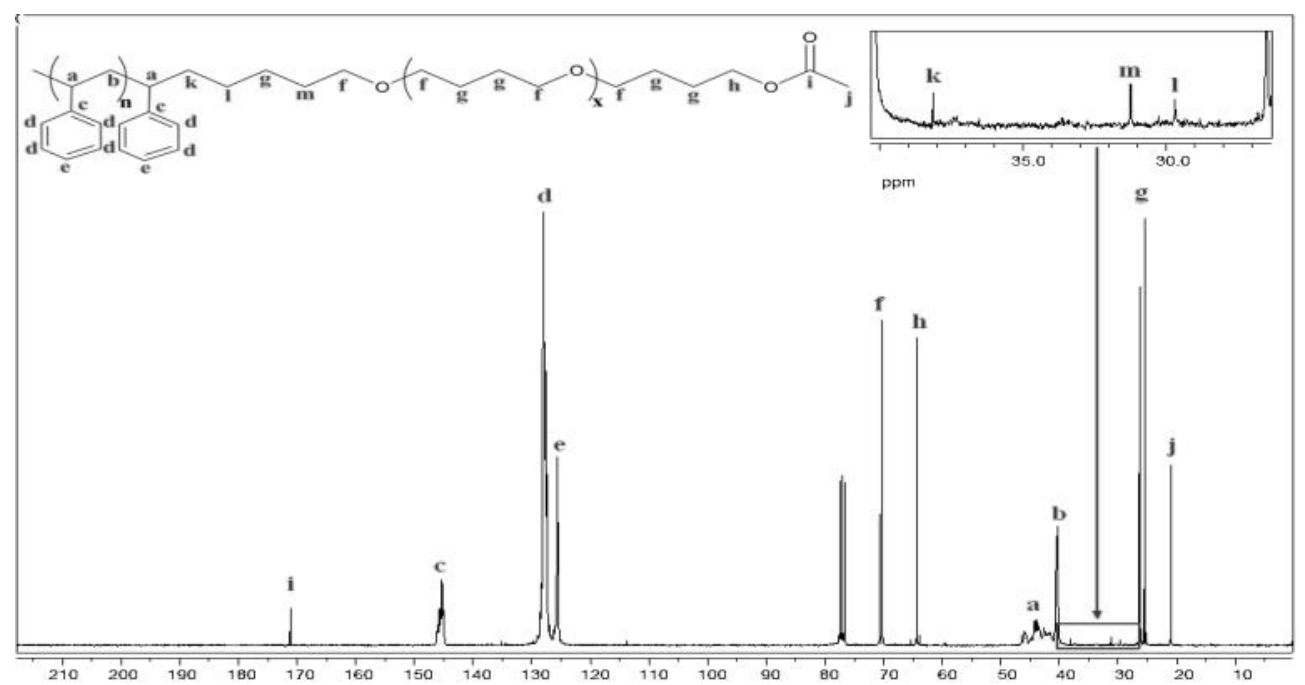

Chemical shift [ppm]

Figure 3: ${ }^{13} \mathrm{C}-\mathrm{NMR}(300 \mathrm{MHZ})$ in $\mathrm{CDCl}_{3}$ of Poly(St-co-THF) (Sample $\mathrm{E}_{2}$ ) 
copolymerization.

Additional analyzes were carried out on the sample $\mathrm{E}_{2}$ to further demonstrate the structure of the copolymer. Spectrometric analyzes: ${ }^{13} \mathrm{C}-\mathrm{NMR}$ and IR of sample $\mathrm{E}_{2}$ are presented in figures 3 and 4 respectively

The ${ }^{13} \mathrm{C}-\mathrm{NMR}$ spectrum (Fig. 3) also proves the presence of both components in the copolymer (ppm): $145.29 ; 127.93 ; 127.62 ; 125.62$ (aromatic carbons of PSt), 43.83 ; 40.34 (aliphatic carbons of PSt). 70.67; $70.24\left(\mathrm{CH}_{2}-\mathrm{O}\right)$ and $26.47 ; 26.20$; $25.48\left(\mathrm{CH}_{2}\right)$ from PTHF. $20.95\left(\mathrm{CH}_{3}\right)$ and 171.14 $(\mathrm{C}=\mathrm{O})$ from acetate of end chains. $64.28 \mathrm{ppm}$ (final $\mathrm{CH}_{2}-\mathrm{O}$ of PTHF linked with acetate of end chains) was clearly visible. The peaks at $\delta=29.67$ and $31.22 \mathrm{ppm}$ were assigned to methylenes in position 5;3 respectively of THF linked to St. The peak at $\delta=38.12 \mathrm{ppm}$ was assigned to methylenes of St linked to THF.

Here, the signals intensities of acetates " $h, i, j "$ (Fig. 3: ${ }^{13} \mathrm{C}-\mathrm{NMR}$ ) were strangely dissimilar. Another thing, these signals were clearly distinctive, contrary to the signals acetates appeared in the previous spectrum "g, h" (Fig. 2: $\left.{ }^{1} \mathrm{H}-\mathrm{NMR}\right)$ of the same sample. This can be explained by the nuclear Overhauser effect (NOE) [14] which results in the case of the ${ }^{13} \mathrm{C}-\mathrm{NMR}$ by the increasing in signal intensity for certain carbons caused from strong dipolar interactions of the copolymer in solution. The interpretation of ${ }^{13} \mathrm{C}-\mathrm{NMR}$ spectrum (Fig. 3) is in conformity with the results published by Cianga et al. [7] and Shimomura et al. [8].

The principal functions present in the product (experiment $\mathrm{E}_{2}$ ) can also be seen by IR analysis (Figure 4). The function ester present in the

Table 2: Results of Products Analysis by ${ }^{1} \mathrm{H}-\mathrm{NMR}$ and ${ }^{13} \mathrm{C}-\mathrm{NMR}$ Spectroscopy

\begin{tabular}{|c|c|c|c|c|c|}
\hline Simple & $\begin{array}{c}\text { NMR } \\
\text { analysis }\end{array}$ & Molecule & Index & Proton/carbon observed & Signal $\delta$ (ppm) \\
\hline \multirow{4}{*}{$\mathbf{E}_{1}:$ PSt } & \multirow{4}{*}{$\begin{array}{c}{ }^{1} \mathbf{H}-\mathrm{NMR} \\
\text { (Fig. 1) }\end{array}$} & \multirow{4}{*}{ St } & $\mathrm{a}$ & Ph-CH- & 1.87 \\
\hline & & & $\mathrm{b}$ & $\mathrm{Ph}-\mathrm{CH}-\mathrm{CH}_{2}$ & 1.45 \\
\hline & & & $\mathrm{c}$ & $\mathbf{2 H}$ (in ortho of phenyl) & 6.60 \\
\hline & & & $\mathrm{d}$ & 3H (in meta and para of phenyl) & 7.06 \\
\hline \multirow{22}{*}{$\begin{array}{c}\mathrm{E}_{2}: \\
\text { Poly(St } \\
\text {-co- } \\
\text { THF) }\end{array}$} & \multirow{9}{*}{$\begin{array}{c}\text { 1'H-NMR } \\
\text { (Fig. 2) }\end{array}$} & \multirow{4}{*}{ St } & $\mathrm{a}$ & Ph-CH- & 1.87 \\
\hline & & & $\mathrm{b}$ & $\mathrm{Ph}-\mathrm{CH}-\mathrm{CH}_{2}$ & 1.46 \\
\hline & & & $\mathrm{c}$ & $\mathbf{2 H}$ (in ortho of phenyl) & 6.61 \\
\hline & & & $\mathrm{d}$ & $\mathbf{3 H}$ (in meta and para of phenyl) & 7.07 \\
\hline & & \multirow{4}{*}{ THF } & $\mathrm{e}$ & $-\mathrm{O}-\mathrm{CH}_{2} \mathrm{CH}_{2} \mathrm{CH}_{2} \mathrm{CH}_{2}-\mathrm{O}$ & 3.44 \\
\hline & & & $\mathrm{f}$ & $-\mathrm{O}-\mathrm{CH}_{2} \mathrm{CH}_{2} \mathrm{CH}_{2} \mathrm{CH}_{2}-\mathrm{O}-$ & 1.64 \\
\hline & & & $\mathrm{i}$ & $-(\mathrm{St})_{\mathrm{n}}-\mathrm{CH}_{2} \mathrm{CH}_{2} \mathrm{CH}_{2} \mathrm{CH}_{2}-\mathrm{O}-$ & $1.23-1.26$ \\
\hline & & & $\mathrm{g}$ & $-\mathrm{CH}_{2} \mathrm{O}-\mathrm{CO}-\mathrm{CH}_{3}$ & 4.11 \\
\hline & & $\mathrm{AA}$ & $\mathrm{h}$ & $-\mathrm{CH}_{2} \mathrm{O}-\mathrm{CO}-\mathrm{CH}_{3}$ & 2.07 \\
\hline & \multirow{13}{*}{$\begin{array}{c}{ }^{13} \text { C-NMR } \\
\text { (Fig. 3) }\end{array}$} & \multirow{6}{*}{ St } & $\mathrm{a}$ & Ph-CH- & 43.83 \\
\hline & & & $\mathrm{b}$ & $\mathrm{Ph}-\mathrm{CH}-\mathrm{CH}_{2}$ & 40.34 \\
\hline & & & $\mathrm{c}$ & $\mathbf{1 C}$ of phenyl linked to methine & 145.29 \\
\hline & & & $\mathrm{d}$ & $\mathbf{2 C}$ in ortho and $\mathbf{2 C}$ in meta of phenyl & $127.93-127.62$ \\
\hline & & & e & 1C (in para of phenyl) & 125.62 \\
\hline & & & $\mathrm{k}$ & $\mathrm{Ph}-\mathrm{CH}-\mathrm{CH}_{2}-(\mathrm{THF})_{\mathrm{n}^{-}}$ & 38.12 \\
\hline & & \multirow{5}{*}{ THF } & $\mathrm{f}$ & $-\mathrm{O}-\mathrm{CH}_{2} \mathrm{CH}_{2} \mathrm{CH}_{2} \mathrm{CH}_{2}$-O- & $70.24-70.67$ \\
\hline & & & $\mathrm{g}$ & -O- $\mathrm{CH}_{2} \mathbf{C H}_{2} \mathbf{C H}_{2} \mathrm{CH}_{2}$-O- & $25.48-26.20-26.47$ \\
\hline & & & 1 & $-(\mathrm{St})_{\mathrm{n}}-\mathrm{CH}_{2} \mathrm{CH}_{2} \mathrm{CH}_{2} \mathrm{CH}_{2}-\mathrm{O}-$ & 29.67 \\
\hline & & & $\mathrm{m}$ & $-(\mathrm{St})_{\mathrm{n}}-\mathrm{CH}_{2} \mathrm{CH}_{2} \mathrm{CH}_{2} \mathrm{CH}_{2}-\mathrm{O}-$ & 31.22 \\
\hline & & & $\mathrm{h}$ & $-\mathrm{CH}_{2} \mathrm{O}-\mathrm{CO}-\mathrm{CH}_{3}$ & 64.28 \\
\hline & & \multirow{2}{*}{$\mathrm{AA}$} & $\overline{\mathrm{i}}$ & $-\mathrm{CH}_{2} \mathrm{O}-\mathrm{CO}-\mathrm{CH}_{3}$ & 171.14 \\
\hline & & & $\mathrm{j}$ & $-\mathrm{CH}_{2} \mathrm{O}-\mathrm{CO}-\mathrm{CH}_{3}$ & 20.95 \\
\hline
\end{tabular}




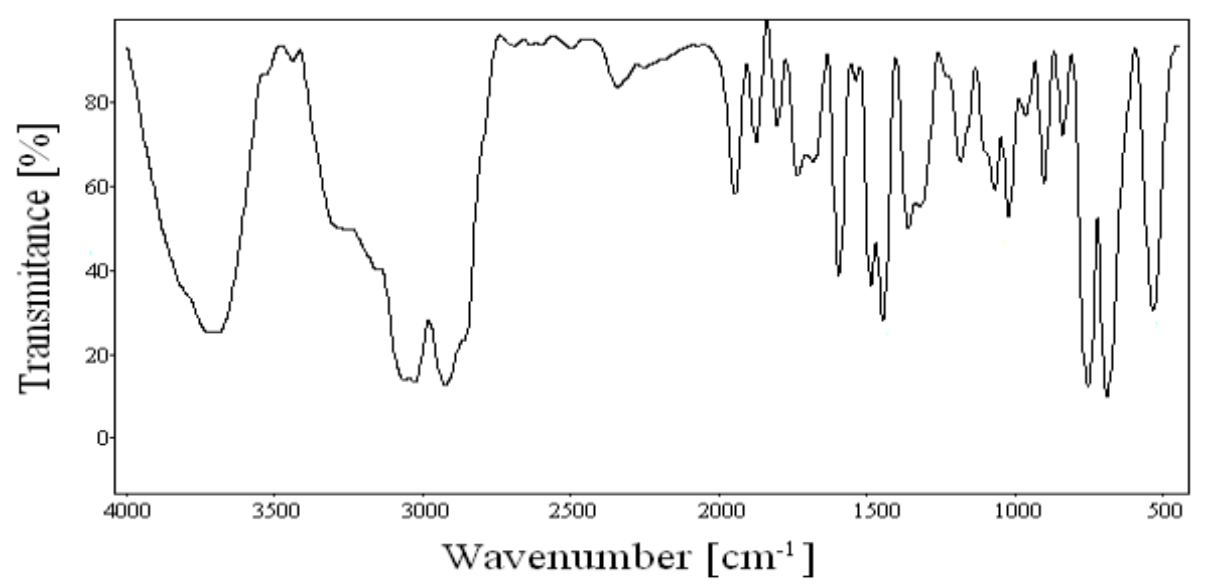

Figure 4: I.R. spectrum of Poly(St-co-THF) (sample $E_{2}$ )

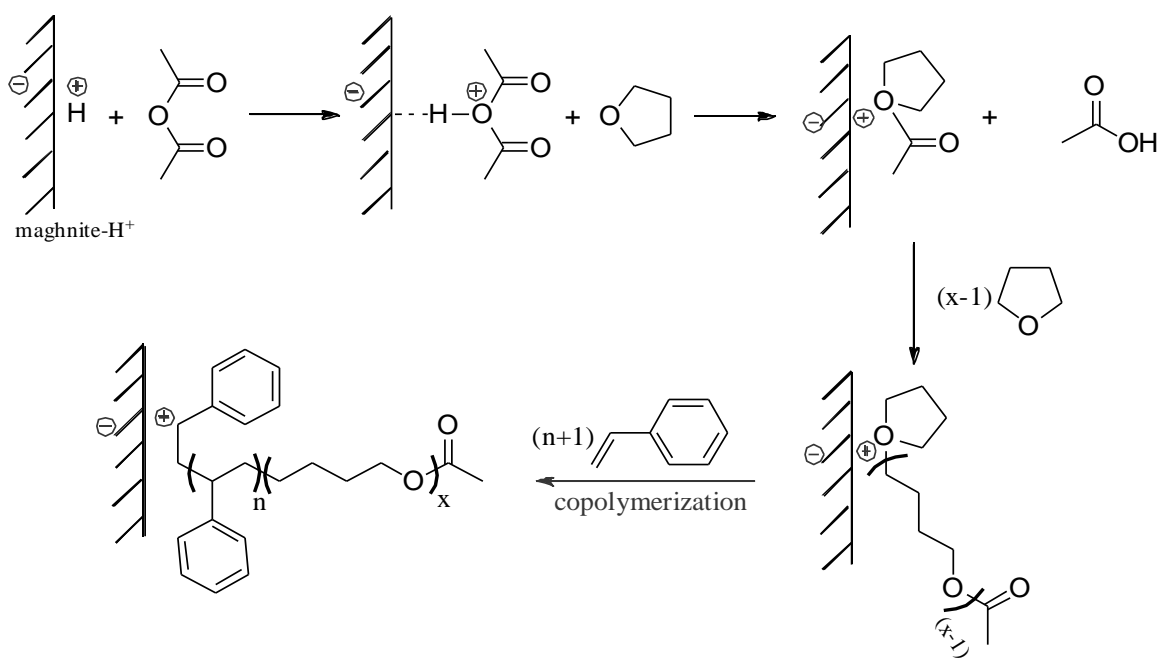

Figure 5: Mechanism Suggested for the Copolymerization of St with THF

acetate of the end of chain, appears clearly in two areas: at $1735.79 \mathrm{~cm}^{-1}$ for $(\mathrm{C}=\mathrm{O})$ group and at $1185.89 \mathrm{~cm}^{-1}$ for the $(\mathrm{C}-\mathrm{O})$ function. The phenyl of St appears in three absorption bands: one on at $1596.99 \mathrm{~cm}^{-1}$ for $(\mathrm{C}=\mathrm{C})$, another at $3028.29 \mathrm{~cm}^{-1}$ for $(\mathrm{C}-\mathrm{H})$ and the last at $755.80 \mathrm{~cm}^{-1}$ for the plan deformation of $(\mathrm{C}-\mathrm{H})$. The ether function appear clearly at $1070.79 \mathrm{~cm}^{-1}$. The wide strip at 3720.29 $\mathrm{cm}^{-1}$ was allotted to the link $(\mathrm{O}-\mathrm{H})$ which was undoubtedly due to a bad drying of $\mathrm{KBr}$ used for this analysis. This interpretation is in conformity with the results published by Hazer [5] and Hizal et al. [15].

\subsection{Mechanism of the copolymerization}

According to the foregoing discussion and the results of product analysis, the following mechanism may be suggested for the resulting reaction of copolymerization induced by $\mathrm{Mag}-\mathrm{H}^{+}$. Protons carried by montmorillonite sheets of $\mathrm{Mag}-\mathrm{H}^{+}$ induced the polymerization; these montmorillonite sheets take place as counter-anions. The first stage was the protonation of AA. Then a molecule of THF attacks on the protonated AA with nucleophilic way. The formed ions oxonium take place in the vicinity of the counter-anion carried by montmorillonite sheets, then there was a nucleophilic attack of the double bond carboncarbon of St on the carbon located in alpha of oxygen charge carrier positive of the chains in growth and now the copolymer was formed.

\section{Conclusions}

The spectrometric analyses ${ }^{1} \mathrm{H}-\mathrm{NMR},{ }^{13} \mathrm{C}-\mathrm{NMR}$ as well as IR has made it possible to highlight the structure of copolymer and these results were in agreement with the former studies. Obtaining copolymer proves that the oxonium ion of THF and the carbonium ion of St propagate the reaction of copolymerization. The AA is essential for the maintenance of the ring opening of THF [9] and the entry in copolymerization. The Mag- $\mathrm{H}^{+}$allowed 
us to obtain extremely pure copolymer in good yield by following a simple experimental condition. These conditions were very favored by industrials.

The copolymerization between these different types of chemical structures family: vinylic and cyclic ether comonomers, can lead to a product whose entire physical, mechanical and chemical properties are news [1]. Research on the physicals and chemicals properties could be carried out in order to find applications for this product.

\section{References}

[1] Odian, G. eds. (2004). Principles of polymerization. Willey Interscience.: John Wiley \& Sons.

[2] Tsukamoto, A.; Vogln, O. (1971). Cationic polymerization. Progress in Polymer Science. 3: 199-279.

[3] Wabnitz, T.; Hatscher, S.; Kashammer, S.; Pinkos, R. (2009). Method for the production of polytetrahydrofurane or tetrahydrofurane copolymers. Patent Application Publication. US 72009/0215971 A1.

[4] Hazer, B. (1991). Synthesis of styrene tetrahydrofuran branched block copolymers. European Polymer Journal. 27: 975-978.

[5] Hazer, B. (1990). Cationic polymerization of tétrahydrofurane initiated by difunctional initiators. Synthesis of block copolymers. European Polymer Journal. 26: 1167-1170.

[6] Yan-Ming, G.; Ting, W.; Yin-Fang, Z.; CaiYuan, P. (2001). Atom transfer radical copolymerization of styrene and poly(THF) macromer. Polymer. 42: 6385-6391.

[7] Cianga, I.; Hepuzer, Y.; Yagci, Y. (2002). Poly( $p$-phenylene) graft copolymers with polytetrahydrofuran/polystyrene side chains. Polymer. 43: 2141-2149.
[8] Shimomura, O.; Lee, B. S.; Meth, S.; Suzuki, H.; Mahajan, S.; Nomura, R.; Janda, K. D. (2005). Synthesis and application of polytetrahydrofuran grafted polystyrene (PS-PTHF) resin supports for organic synthesis. Tetrahedron. 61: 12160-12167.

[9] Ouis, N.; Benharrats, N.; Belbachir, M. (2004). Tamazert kaolin as catalyst in synthesis of polytetrahydrofuran. Comptes Rendus Chimie. 7: 955-962.

[10] Breslow, R.; Denonne, F. eds. (2001). La chimie aujourd'hui et demain. De Boeck \& Larcier.: De Boeck Duculot.

[11] Belbachir, M.; Bensaoula, A. (2006). Composition and method for catalysis using bentonites. United States Patent 6,274,527 B1.

[12] Verebélyi, K.; Iván, B. (2012). Cationic polymerization of styrene by the TiCl4/N,N,N',N'-tetramethylethylenediamine (TMEDA) catalyst system in benzotrifluoride, an environmentally benign solvent, at room temperature. Polymer 53: $3426-3431$.

[13] Gottlieb, H. E.; Kotlyar, V.; Nudelman, A. (1997). NMR Chemical shifts of common laboratory solvents as trace impurities. Journal of Organic Chemistry. 62: 75127515 .

[14] Brandolini, A. J.; Hills, D. D. eds. (2000). NMR spectra of polymers and polymer additives. Mobil Chemical Company.: Marcel Dekker.

[15] Hizal, G.; Tasdemir, H.; Yagci, Y. (1990). Block copolymers by combination of cationic and radical routes: 5. Polymerization of styrene initiated by 4,4'-azobis(4cyanopentanoyl chloride). Polymer 31: 18031806. 